\title{
Out of Conclusion - On Recurrence and Open-endedness in Life and Analysis
}

Frederiksen, Martin Demant; Dalsgård, Anne Line

Published in:

Social Analysis: The International Journal of Anthropology

DOI:

$10.3167 /$ sa.2013.570104

Publication date:

2013

Document version

Early version, also known as pre-print

Citation for published version (APA):

Frederiksen, M. D., \& Dalsgård, A. L. (2013). Out of Conclusion - On Recurrence and Open-endedness in Life and Analysis. Social Analysis: The International Journal of Anthropology, 57(1), 50-63.

https://doi.org/10.3167/sa.2013.570104 


\title{
Out OF CONCLUSION
}

\section{On Recurrence and Open-Endedness in Life and Analysis}

\section{Anne Line Dalsgaard and Martin Demant Frederiksen}

\begin{abstract}
Based on long-term fieldwork in Northeast Brazil and the Republic of Georgia, this article explores how open-endedness can be incorporated into ethnographic analysis and writing, not as the empirical object, but as a basic condition for knowledge production. In the empirical contexts that we describe, daily life is marked by poor prospects and the absence of possibility, especially for young people. Rather than letting this guide our analyses, this article argues for the necessity of paying attention to the openness and potential of experienced moments of change. We propose that even relapses into former habits and predicaments present the potential for change on a subjective level. In the process of putting informants' stories into words and analysis, we revisit both field and text, constituting a hopeful practice similar to that of our informants.
\end{abstract}

Keywords: analysis, Brazil, Georgia, hope, open-endedness, recurrence, uncertainty, youth

\section{Endings}

In the end, the business card actually turned into a business. In the end, the business card actually turned into a business. In the end, the business was substituted by a non-existing website. In the end, the business was substituted by a non-existing website. In the end, nothing really happened.

in the end, nothing really happened.

In the end, he became a decent worker at the factory.

In the end, he became a decent worker at the factory.

In the end, he was caught by the police and arrested for theft. in the end, he was eaught by the poliee and arrested for theft. In the end, he took another shower.

in the end, he took another shower. 


\section{Recurrence}

It began with a review of literature on marginalized youths. At the time, Martin Demant Frederiksen had finished his fieldwork in Tbilisi for his master's thesis and had to write an exam paper on a topic of his choice that related to his research. Martin contacted his future supervisor, Anne Line Dalsgaard, and together they discussed the possibility of turning the review into a comparative article based on his work on young people in Georgia and her work in Brazil. The writing began as an attempt to criticize the then current tendency within anthropology and related fields to consider marginalized youths as either victims of structural constraint or agents in their own lives. They took as their point of departure the stories of two individuals, Rezo and Fábio, whom they knew well and whom they saw as being neither victims nor efficient agents. The first draft eventually turned into a grant application with two colleagues to do research on questions of youth, marginality, and futurity. The project was funded, and Martin and Anne Line both returned to their field sites where new data emerged. Of course, the lives that they had focused on during previous fieldwork had moved on while they had been away. The initial conclusion of the first draft had to be changed, and so a new draft was written. Meanwhile, they had become interested in writing styles and questions concerning the anthropologist's possible responsibility in relation to the lives she or he describes.

A year or so went by. The stories of the two young men in Georgia and Brazil moved on yet again. Anne Line lost contact with the informant she was writing about and presumed he had gotten himself into serious trouble. Martin, on the other hand, had heard from his informant that he had, after several years of disappointment, finally succeeded in establishing an actual business. Yet another draft, with new endings, was written and later discussed at a workshop entitled "Time and the Field." Comments from other participants were included, and new ideas for restructuring the argument and ending were written into the text. The initial literature review was taken out, as it was no longer relevant. An invitation to submit the article as part of a special issue of Social Analysis was accepted, and the article was finalized and sent in. Almost a year passed without notice, during which new fieldwork, new data, updates on the worries and troubles of informants, as well as their missed chances and new prospects, all came about. When the anonymous reviews were received, certain things in the article no longer seemed right. A new argument emerged out of corrections and adjustments, and a new theory had to be found. Once again, this meant beginning anew.

\section{Holding On}

A business card. He holds it in his hand as he approaches the anthropologist in the underground passageway. He is a tour guide, or at least he hopes that one day he will be. The card features an image from the animated film Ice Age 2: a small animal is clinging to a cliff, denying the fact that it is, inevitably, going to fall. 
"Life is adventure or nothing at all," the card reads. The man approaches the anthropologist with the words "Could you help me? I have this business." The anthropologist looks at the business card and wonders why the web address has been crossed out and there is no office address. Does the business exist or not? It is hard to tell; maybe it does and does not at the same time. In the Republic of Georgia, in the capital city Tbilisi where the man lives, chances are few. He has an education but lacks the network and connections that are so vital in the country if one wants to advance or get a job. But what if he had his own business? Or it at least seemed as though he did? Would the foreigners living in the expensive city center hotels then maybe consider hiring him as their tour guide? Could he get business by pretending to have one already? Or is he, like the animal on the card, simply clinging to a cliff with his nails, destined to fall? Is he merely living in the future with no reference to his present situation, or is he making a future? Rezo is his name.

Somewhere else. A shower. A young man, brown skinned, with a hideous scar on his right thigh. He lives in one of the poorer parts of Brazil in circumstances that are not conducive to being well-groomed. The house in the favela (shanty town) where he lives is hot during the daytime, and the steps up the hillside to get there are many. He used to work in a factory, carrying heavy loads, and he dreamed of becoming a truck driver to escape from the meaningless toil and the commandments of others. To be allowed a driver's license at the factory, he needed to talk to the right people. But how? One day, during his lunch break, he sat down at the table next to Mauricio, a superior with influence. But Mauricio got up and moved to another table. "It was my smell of sweat. Brazil is divided into those who smell of sweat and those who do not. Like Mauricio.” The young man refuses to be what they turn him into. But can he wash off a predestined future? The question is asked in every shower, in the changing of shirts, and in the honesty he projects, because he is the kind of person who could just as well be a reliable truck driver. Fábio is his name.

\section{Introduction}

Every moment has the potential to lead to something new; the question is how this potential is released. One may wait for the unexpected to emerge, assuming that "there is always the possibility, as in any mystery story, that factors will emerge and come into play of which one has no inkling, and that these unforeseen factors will free the future from the impress of the past" (Jackson 2005: 14). One may passively wait for 'luck' or 'miracles' in what Ghassan Hage (2003: 12) calls a "hope against life." And, in a way, this is what Rezo and Fábio do. They wait for the right moment to appear, the moment when someone calls Fábio forward and acknowledges his honesty and hard work, and the moment when Rezo meets the right kind of tourists, ready for a dubious adventure. But they do not do so passively. In their revisiting of the recurring experience of setbacks, of impossibilities, there is a manifestation of a vibrant life, of a kind of unjustified promise. They could just as well give up, but they do not. They 
begin again. The potential of every new beginning is not an empirical fact. It may rather be an empirical non-fact, since a potential cannot, by definition, have the factive quality of a fact. A potential is a capacity of being or becoming, and as such it challenges the established way of arguing in anthropology for the credibility of our analysis. How do we write about something that is present by way of absence or, rather, by way of not yet being a fact?

Anthropologists have written about the subjunctivity and managing of uncertainty in human life (Good and Good 1994; Steffen et al. 2005; Whyte 1997). These analyses have argued that agency unfolds in even the most difficult situations - that "[h]umans are never merely victims of fate" (Jenkins et al. 2005: 11) and that people generally struggle to achieve some sense of control in life (Jackson 1998). These studies have emphasized the negotiation of uncertainty and the often ingenious handling of it. However, ours is less an interest in negotiation and problem solving in relation to the question of agency and more a look to the manifestation of the subject over time. We simply ask how we can understand the loops in the trajectories of life that we observe, if not as repetition alone. Or, put differently, is there more to recurrence than mere repetition? Drawing primarily on the work of Hirokazu Miyazaki, we think of the process of repetition as a "method of hope ... predicated on the inheritance of a past hope and its performative replication in the present" (Miyazaki 2004: 139). However, where Miyazaki looks at hope in a ritual, that is, in a collective context, we try to understand a subjective process by way of his insight.

Our data stem from ongoing fieldwork in the Republic of Georgia and in Northeast Brazil. Life in the two chosen regional contexts is marked by poverty and disappointment, and young people in particular find it hard to uphold aspirations for the future. Even though Brazil today is experiencing enormous growth and reimagining of the future, this does not change Fábio's situation. He and many others of his age grew up in the depressing 1980s and early 1990s, and they had little to look forward to when they were younger. Similarly, although more stable today than in the 1990s, the social and political situation in the Republic of Georgia continues to leave few, if any, options for Rezo.

\section{Stories}

Rezo was 20 years old when Martin first met him in an underway passage. What distinguished Rezo from his peers was that, in describing his own situation, he acknowledged that his chances were near nil. As he noted on one occasion, "It is not really nice to talk bad about the country you live in but ... Georgia has some problems you know. For example, if you want a job, you have to know somebody, you know? Have relations." Rezo was referring to the fact that getting a job often depended on having a connection to someone who could either hire you or make sure that you were hired. It was clear to him that he did not have any such relations and did not see himself as having any obvious chances. He had begun to distrust the entire official system, and, due to changes in the educational sector, the courses he had taken in 'hospitality and hotel training' 
were considered 'too old' to be of any real use (although he had graduated only recently), making it impossible for him to find a job in the hotel industry. Furthermore, the hopes for the future expressed by the Georgian government and various institutions taking care of unemployed or homeless youths did not fit with his situation. But in some respects, it seemed that the recognition of not having any real chances and of the apparently hopeless situation motivated Rezo to continue to be on the lookout.

When Martin returned to Tbilisi after a year's absence in the spring of 2007, Rezo was thus still looking for a job, still looking for a girl to marry, and still walking around the city in search of possibilities-or looking for possibilities to find him. He was, in this sense, not different from many other young men in Tbilisi who were waiting for a chance to move on in life-except for one thing. He proudly carried a business card in his pocket. The business, he explained, did not actually exist yet. He did not have an office, and he had crossed out the web page link on the card because it linked to a non-existent page. And if he managed to get some customers, he was not sure what he would do or where he would take them. Still, he found that in order to do business he needed to have a business, and the business card served as an intermediate stage, an imagined future that was yet to become concrete. The image of the 'squirrel rat' from Ice Age 2 was striking. In the movie, the rat is on a continuous chase to protect a small nut and to regain it when it is lost. For reasons that Rezo probably did not have in mind, the image of the squirrel rat seemed to correspond well to his situation. On the one hand, here was a young man desperately trying to hold on to something, but it was also an image of the fruitless end result of the eternal chase-with a possible business substituted for a nut. But this, of course, was Martin's interpretation, not Rezo's.

In Brazil, Fábio had almost given up waiting for the future that he wished for-a truck driver's license and a job as a driver. Even so, the possibility that he could as well have become a truck driver, if he had had a little help, seemed to change the situation he was in-or at least to keep it open. He was almost predestined to prison and an early death: when he was still young, he got involved in criminal activities like so many young boys in the neighborhood where he lived (Dalsgaard 2004; Dalsgaard et al. 2008). His brother was killed when they were out stealing. His friend was killed when they were high on drugs together, riding on the roof of a train. Fábio himself later went to prison when he was caught selling drugs. Although he got out with the help of a lawyer who could see his potential, he was soon wanted by the police again. Through the years that followed, he got himself into more and more criminal activities, and at the time of writing he is wanted by the police for having been part of a gang that has committed several serious crimes. And yet he somehow escapes the lot that befalls others like him. When Anne Line first met Fábio, he had already lived longer than many of his age mates. Through all that he has been involved in, he has, to some extent, been able to stop and withdraw when withdrawal was still possible. People help him despite the things he has done. They hide him, set him up with a job as a construction worker in the city he has fled to, and get him false papers when he needs them. According to his mother, this 
willingness to help springs from Fábio's sincere attitude, which people recognize and respect. The sincerity seems to be a result of his self-respect, which shows in small, everyday acts.

What is self-respect? In Georgia, it is your behavior when you toast a friendship, those who died, or those who will come. It is generosity toward friends, which is always an active choice (Frederiksen 2011a). In Brazil, it is the simplicity with which you meet everyone, without anger or resentment, and the cleanliness that even the poorest can produce. It is the ability to resist 'heating up the head', as people say, like when Fábio said: "I will conform and continue my life forward, not look back. Because if a person looks back at the things he already did, what will you get? Nothing! You have to look forward ... you have to try!" Self-respect is thus closely related to the respect or recognition bestowed by others, but every moment involves a choice and is inherently dangerous, as recognition from others can be withdrawn. Recognizing the potential of a moment is thus also a hesitation to conclude. Somebody may see who I really am, despite the neglect and disregard of others.

Fábio seems to have let in some hope by allowing the agency of God a place in his life, while staying as clean and prepared as possible. His acts are not conspicuous. They mainly consist in withdrawing and not despairing, and thus staying alive against all odds. But something in him is active, as if the pain of knowing his situation keeps him awake. Rezo mimicked something that did not yet exist: the business card contained Rezo's hope of something coming into being, a not yet that, although non-existent, provided him with an incentive to keep striving. Moltmann's (2004) notion of hope as that which has no place 'yet' (but is immanent) seems pertinent here. Neither of the young men is in a safe haven, though. When Anne Line last heard from Fábio’s mother Neide, she was angry with him because he kept asking for money through his girlfriend, who phoned Neide. Fábio could no longer work where he was, his girlfriend was tired of supporting him, and Neide had her own worries. Frustration was building up on all sides, and Neide was afraid that Fábio would do "something stupid" and get caught by the police. Rezo managed to get his first customers, and the tours went well, regardless of the fact that he had no previous experience of actually conducting tours outside Tbilisi. In e-mails and phone calls, he told Martin how he still had a long way to go; he wanted to learn foreign languages and to create a website. He was not sure how to accomplish this, but his endeavor no longer seemed destined to the wild goose chase that might never end, as Martin had originally assumed. Rezo had in fact succeeded in turning his imaginary vision of his own future into a present reality that offered him direct possibilities and gains. But when the conflict between Russia and Georgia broke out in August 2008, it dealt a serious blow to the tourism industry in Georgia (Frederiksen 2011b). E-mails from Rezo stopped.

Both stories could end here with the conclusion that Fábio managed to stay clear of prison due to his hope of one day becoming a truck driver, while Rezo managed to get a business started against all odds. But it does not seem right to end here. Fábio and Rezo have to face new mornings with sincere doubts and risks. Both are likely (as our knowledge of them indeed has shown) to return to 
previous conditions and practices-showering, distributing business cards, or doing whatever is needed to hold on to their potential. It is this process of recurrence-the continual setbacks and the starting anew-that has caught our interest. Something occurs in the recurrence. A kind of continuity appears. It may be imagined, but it nevertheless has real consequences (cf. Jenkins et al. 2005: 10).

\section{Hope}

In his book I Am Dynamite, Nigel Rapport (2003: 14) writes that "construing and pursuing one's life as an individual project is a route to a dignified and accomplished life." This ongoing accomplishment is, to Rapport, the unfolding of an existential power, "the force, the will, the energy, in a word the agency, whereby individuals produce effects in their worlds-effect worlds, in fact" (ibid.: 75). While the individuals that Rapport takes as his "Everyperson" (ibid.: 15; cf. Rapport 2010) are people who, at least so it seems, are more capable and single-minded than Rezo and Fábio, we find that Rapport's insistence on the potential openness of every life has a bearing in relation to our cases as well. Neither Rezo nor Fábio moves through life as an "individual as projectile" (Rapport 2003: 149), but both possess an individual project, a 'distinctness' that manifests itself through their various acts (or non-acts) in a continual process of becoming, almost as an active waiting (cf. Jeffrey 2010).

From a common-sense perspective, human life is at all times open-ended, since no one, per definition, knows the end before it is reached. Hence, we may argue that as long as we in our analysis hold on to one view of what the future might bring, be it solely pessimistic or hopeful, we do not fully capture life as lived. A finished story is somehow 'over', lifeless. As John Berger (1982: 284) sees it, stories walk like men, and the suspense does not relate to the plot as much as to the passage from one step to another. Thus, knowing the end is not as interesting as following the process. What will happen next? This openness entails hope, because as long as the story has no conclusion, it can always be different. In both our fields, daily life is filled with seemingly mundane routines-or recurrences-that partake in upholding this openness to the world and the future. It is the propensity for change and the potential of each moment, we believe, that must be kept in mind while engaged in anthropological writing.

Indeed, hope is praxis, keeping things open, as Miyazaki (2006) writes, and not an emotional state of positive feeling about the future or a religious sense of expectation. It is a method of radical temporal reorientation of knowledge, a process of looking forward instead of backward, as Miyazaki (2004) describes it in relation to a gift-giving ritual in Fiji. The ritual was not designed to generate hope, as Miyazaki initially understood it; rather, it was in itself a hopeful praxis, where the maintenance of a prospective perspective was at the heart of its performance. Hope, he understood, was the submission, ritual after ritual, to keeping the future open by holding one's agency in abeyance, leaving the fulfillment of the story to higher powers. There are, we believe, striking 
parallels between Miyazaki's description of gift-giving rituals and the lives of Fábio and Rezo. The maintenance and repetition of everyday routines, such as Fábio taking his showers and Rezo polishing his shoes before venturing out onto the streets with his business card, are both forms of hopeful praxis that render their lives-and stories-open.

There are, writes Richard Wilk (2009: 144), "subtle and often subjective differences between the routines which make life possible, and those which make living miserable." In the repetitive gestures involved, for instance, in t'ai chi, repetition is aimed at perfecting and refining the act that is repeated (ibid.). But the return to and repetition of a previous condition or action (i.e., recurrence) may also be conducive to change. It is, we believe, in this sense that we can understand recurrence as a practice of hope. Indeed, hope and hopelessness are mutually related-two sides of the same coin (Crapanzano 2006: 17; see also Zigon 2009). At times, in a paradoxical manner, there is no way out of hopelessness but by accepting it as part of life. We often find hope in that which is not-not only because hope is the 'not yet', but also because hope has to do, in many cases, with not doing something that one would otherwise have done.

Repeated acts or withdrawal from action may have the quality of similarity, but they are not necessary identical-and this is the crucial point. Repetitions rarely (if ever) take place in a social vacuum. The social context in which they occur may change, and coincidence may allow for 'vital conjunctures' (Johnson-Hanks 2002, 2005) that, seen in retrospect, transform the trajectory of a life. The repeated acts may be interpreted in ways that result in alteration. For instance, Fábio's insistent showering may be recognized by others as a sign of decency, which changes their perception of him as a person, and Rezo's distribution of his business card may be read by a passer-by as a sign of persistence, qualifying him for a job. It is impossible to foresee such potentialities in any exact manner, but their possible presence is at the very heart of the hopeful aspects of recurrence.

In his article "A Day in the Cadillac," Morten Pedersen (2012) describes a hopeful day with a group of young men in Ulaanbaatar, Mongolia, and argues that otherwise heterogeneous and disparate impressions of self and situation are gathered into fragile assemblages during such moments of hope when one is seen by oneself and others as a whole person. Such moments of joyful realization and prospect are probably not absent in Rezo's and Fábio’s lives, even though we have not been part of them. But we have found a different kind of wholeness: one that emerges out of a continuous process of revisiting (our informants' setbacks as well as our returns to the field). The process of revisiting leaves impressions that add up to more than their sum, as if in a montage, where the simultaneity of often different impressions creates the impression of something otherwise not perceptible (Dalsgaard 2013; Eisenstein 1972: 90). This impression of encompassing wholeness belongs to the viewer, and, therefore, what we try to grasp here does not necessarily contradict Pedersen's description of his friends' moments of coming together. Ours is an interest in the persistence that keeps Rezo and Fábio going. The 'viewer', as we see it, is not only us, the visitors, but also Rezo and Fábio, who are witnesses to their own 
lives. However, the existence of this inner continuity is inferred by us and not empirically justified, except for the fact that it manifests itself over time as persistence despite setbacks. As the filmmaker Sergei Eisenstein (1972) writes, only when time is introduced may a kind of wholeness emerge as a sensed overtone. Motion and rhythm are needed for this unifying overtone to appear: "In the three-dimensional space it is not spatially possible to represent it; only in the four-dimensional space (three plus time) does it emerge and exist" (ibid.: 106-109; our translation).

\section{Writing}

As stated at the beginning, the pattern of recurrence in the two stories only appeared to us as we kept returning to the field. In revisiting our fields, we have both returned to social realities we know well and interviewed young people we have known for a decade or more. Thus, we are addressing a question related to longitudinal studies: Is it the same continuous social reality we return to? If so, what is the character of the continuity? And if not, how do we allow for the unexpected to occur when experience tells us how things are most likely to develop?

In our analyses, we, the anthropologists (and markedly within youth studies), tend to become the judges of whether the hopes of our informants should be deemed prospective or deceptive. In other words, we tend to write analyses that are either too pessimistic or too optimistic because we wish to determine the future or come to terms with it in a very literal sense. This, we believe, is a problematic that can be traced back to the traditions of narration that dominate our ideas of good analysis. The full meaning of a story, Hannah Arendt ([1958] 1998: 192) tells us, reveals itself only when it has ended. It is therefore not until after the fact that we can fully grasp what was at stake in a given context. With a focus on the future, however, it is impossible to get beyond the fact, as the future continuously turns into something that is new and not yet tested. Every time we returned to the field, our conclusions or 'endings', so to speak, were put to shame by the course of events.

The method of fieldwork allows us to follow people in the present and to listen to their stories about the past. But the stories and lives of our informants do not come to a halt when we as fieldworkers return to our universities and are required to 'get something out of' the days we spent in the field. For our informants (and for us while it happened), the moments we spent together were open-ended and part of the process of life, but for the analytical mind, 'life as lived' is soon turned into a past from which we distance ourselves and that we objectify. Reflection upon past moments is inherent in meaningmaking (cf. Muzzetto 2006), but for our informants reflection is still part of an ongoing process. In our analyses, however, we are seldom aware of the futureoriented aspect of reflection, of the consequences of our thinking. This temporal inequality is a crucial difference between lived moments and written, and hence objectified (maybe even reified), pasts that can be taken into account in 
analysis. As long as the future is open for our informants, the new and unexpected may still happen. One way of coming to terms with this, we believe, is to let the time of the field, including recurrence and potential, be reflected, not only in our analysis of the field, but also in the text itself.

Such a focus on the relation between field, time, and text in some ways relates to Johannes Fabian's (1983) much-quoted volume Time and the Other. Here Fabian argues for a style of writing that incorporates concepts of history and time as a means of portraying coevality between ethnographer and informants by, among other things, avoiding the ethnographic present that freezes societies in time. As Kevin Birth (2008: 4) sums up Fabian’s argument: “Stating that 'The $\mathrm{X}$ are matrilineal' implies that the $\mathrm{X}$ have always been and always will be matrilineal even though all societies change ... Thus, the ethnographic present removes the Other from the flow of time and denies the human propensity to change." We agree with Fabian that freezing our informants in time denies them the propensity to change in the future, but we wish to take his argument one step further in stating that 'freezing in time' is not just a matter of grammar. Our narrative style that leads toward conclusion is a much stronger denial of openness and change, at least in the way that anthropologists usually employ it.

Conclusions about the present most often involve implicit predictions about the future, but it is difficult, perhaps even hazardous, to predict what will happen to persons or societies, as Jeremy Boissevain (1992) has found. Returning to the same field over a period of years made him aware of the relativity of the social life he was studying. When returning to the field after a period of several years, and looking back on his previous work, he could see how his attempts to predict what might happen did not correspond to reality. The relativity of the moment makes it impossible to foresee exactly what the moment will turn into. Boissevain concludes that it is essential to place one's analysis "in a time frame that provides a longer perspective than the few years you have personally experienced. This means more history, more examination of the past" (ibid.: 78). But as Birth (2008) has so precisely observed, the past is never just one, and to give it a place in analysis means first of all knowing which past is at play in the given lives under study. Which personal experiences, concepts of time, and culturally shared ideas are being combined? Placing ourselves and our informants in time-sometimes shared, sometimes not-is thus as much a phenomenological endeavor as a historical one.

Likewise, a focus on futurity is necessarily phenomenological since even the discourses about future outcomes are lived, insofar as they are meaningful to somebody (Frederiksen 2011a). To write in a future-oriented way does not imply prediction. In fact, it means quite the opposite, namely, that anything can happen, be it felicitous or not, as the future is inherently unknowable. Indeed, as Miyazaki (2004: 8) notes: "The retrospective treatment of hope as a subject of description forecloses the possibility of describing the prospective momentum inherent in hope. As soon as hope is approached as the end point of a process, the newness or freshness of the prospective moment that defines that moment as hopeful is lost." A main objective of this article, therefore, has 
been to explore whether it is possible or maybe even necessary to deploy a sense of open-endedness in our analyses, thus highlighting the fact that life is a process that continuously extends into the future.

\section{Endings?}

For Rezo's and Fábio's stories to be finished, it would mean that they had died. Fábio is certainly on thin ice, as he is sought by the police, and although Rezo might have made progress with his tourist agency, he will be eager to achieve further success and will have to fight to keep his business going amid the challenges of the societal changes surrounding him, not least the recent war with Russia that turned many young Georgian men's lives into a question of life and death. We cannot know if Fábio and Rezo (or we) will be here 10 years hence. When Anne Line is back in Denmark, talking with Fábio's worried mother on the phone leaves hope open yet also demonstrates that things are not well. Had he been safe, his mother would not have called or been worried about where he is. Fábio is not safe-but, on the other hand, he is not dead. Receiving Rezo's e-mails is likewise keeping a hope alive. And yet, would Rezo write if he had better things to do? Are the recently missing e-mails in Martin's in-box a sign of trouble or of animated progress? These omens are full of promise but also of uncertainty, and they give rise to questions that keep the relation to the field vibrant. The unfinished relationship is productive, like a stone in the shoe that keeps disturbing us. Indeed, as Anthony Cohen (1992: 2) has observed, the writing of ethnography is a provisional endeavor in the sense that our understanding of what took place during fieldwork is likely to change over time. A good example of this is Renato Rosaldo's (2004) classic description of bereavement among the Ilongot and how his understanding of data changed over time as a result of the death of his wife. Rather than seeing this instability as a troublesome aspect of knowledge production, we (and Cohen) find it to be an inescapable condition to be met and explored creatively.

In constantly rewriting this article, new endings have been designed in order to test various possibilities, and these have in time opened up new questions and perspectives that have come to life. Numerous sections and paragraphs have been written only to be cut out later, used for something different or left in a drawer. The recurrence has in many ways created its own form of excess. Some arguments have been lifted into other articles, an entire research project was funded and concluded in the process, and new ideas for other projects have emerged. You could say that the deferred concluding of this article is just a sign of long-windedness and lack of determination. But we will argue that there is more to it than capriciousness. In the prolonged process of writing, we observed something that would probably not have appeared in a less hesitating analysis: the truth about an individual life (and hence about a particle of the possible) is discernible only in the sameness of its varied, often divergent manifestations. 


\section{Acknowledgments}

The authors would like to thank the participants of the workshop "Time and the Field," which was held at the August 2009 Megaseminar of the Danish Research School of Anthropology and Ethnography, as well as Susanne Højlund and Lotte Meinert for their constructive comments on an earlier version of this article. Morten Axel Pedersen provided valuable suggestions during the finishing process. The article, to which both authors have contributed equally, has been written as a tribute to our mutual friend Marie Højlund Bræmer.

Anne Line Dalsgaard is an Associate Professor at Aarhus University. Based on extensive fieldwork in Northeast Brazil since 1997, she has published several articles on motherhood, youth, violence, and temporality. Her book Matters of Life and Longing: Female Sterilisation in Northeast Brazil (2004) has been translated into Portuguese and was awarded an Honorable Mention by the Eileen Basker Memorial Prize committee of the American Anthropological Association in 2004.

Martin Demant Frederiksen holds a PhD in Social Anthropology and is currently an external lecturer in the Department of Cross-Cultural and Regional Studies, University of Copenhagen. His research interests include time, urban planning, materiality, and morality. Beginning in 2005 and up to the present, he has conducted fieldwork in Batumi and Tbilisi in the Republic of Georgia. He is the author of a forthcoming title, Young Men, Time, and Boredom in the Republic of Georgia (2013).

\section{References}

Arendt, Hannah. [1958] 1998. The Human Condition. 2nd ed. Chicago: University of Chicago Press.

Berger, John. 1982. “Stories.” Pp. 277-291 in Another Way of Telling, ed. John Berger and Jean Mohr. London: Writers and Readers.

Birth, Kevin. 2008. "The Creation of Coevalness and the Danger of Homochronism." Journal of the Royal Anthropological Institute 14, no. 1: 3-20.

Boissevain, Jeremy. 1992. "On Predicting the Future: Parish Rituals and Patronage in Malta.” Pp. 68-80 in Contemporary Futures: Perspectives from Social Anthropology, ed. Sandra Wallman. London: Routledge.

Cohen, Anthony P. 1992. "Post-fieldwork Fieldwork." Journal of Anthropological Research 48, no. 4: 339-354.

Crapanzano, Vincent. 2006. Imaginative Horizons: An Essay in Literary-Philosophical Anthropology. Chicago: University of Chicago Press.

Dalsgaard, Anne Line. 2004. Matters of Life and Longing: Female Sterilization in Northeast Brazil. Copenhagen: Museum Tusculanum Press. 
Dalsgaard, Anne Line. 2013. “Being a Montage.” In Transcultural Montage, ed. Christian Suhr and Rane Willerslev. New York: Berghahn Books. Forthcoming.

Dalsgaard, Anne Line, Mónica Franch, and Russell P. Scott. 2008. "Dominant Ideas, Uncertain Lives: The Meaning of Youth in Recife." Pp. 49-73 in Youth and the City in the Global South, ed. Karen T. Hansen in collaboration with Anne Line Dalsgaard, Katherine V. Gough, Ulla A. Madsen, Karen Valentin, and Norbert Wildermuth. Bloomington: Indiana University Press.

Eisenstein, Sergej. 1972. Udvalgte Skrifter. Holstebro: Odin Teatrets Forlag.

Fabian, Johannes. 1983. Time and the Other: How Anthropology Makes Its Object. New York: Columbia University Press.

Frederiksen, Martin Demant. 2011a. "Haunted by Time: Brotherhoods and Temporal Margins in the Republic of Georgia.” PhD diss., Aarhus University.

Frederiksen, Martin Demant. 2011b. "Good Hearts or Big Bellies: Dzmak'atsoba and Images of Masculinity in the Republic of Georgia.” Pp. 165-187 in Young Men in Uncertain Times, ed. Vered Amit and Noel Dyck. New York: Berghahn Books.

Good, Byron J., and Mary-Jo Del Vecchio Good. 1994. "In the Subjunctive Mode: Epilepsy Narratives in Turkey." Social Science \& Medicine 38, no. 6: 835-842.

Hage, Ghassan. 2003. Against Paranoid Nationalism: Searching for Hope in a Shrinking Society. Sydney: Pluto Press.

Jackson, Michael. 1998. Minima Ethnographica: Intersubjectivity and the Anthropological Project. Chicago: University of Chicago Press.

Jackson, Michael. 2005. Existential Anthropology: Events, Exigencies, and Effects. New York: Berghahn Books.

Jeffrey, Craig. 2010. Timepass: Youth, Class, and the Politics of Waiting in India. Stanford, CA: Stanford University Press.

Jenkins, Richard, Hanne Jessen, and Vibeke Steffen. 2005. "Matters of Life and Death." Pp. 9-30 in Steffen et al. 2005.

Johnson-Hanks, Jennifer. 2002. "On the Limits of the Life Cycle in Ethnography: Toward a Theory of Vital Conjunctures.” American Anthropologist 104, no. 3: 865-880.

Johnson-Hanks, Jennifer. 2005. "When the Future Decides: Uncertainty and Intentional Action in Contemporary Cameroon.” Current Anthropology 46, no. 3: 363-385.

Miyazaki, Hirokazu. 2004. The Method of Hope: Anthropology, Philosophy, and Fijian Knowledge. Stanford, CA: Stanford University Press.

Miyazaki, Hirokazu. 2006. "Economy of Dreams: Hope in Global Capitalism and Its Critiques.” Cultural Anthropology 21, no. 2: 147-172.

Moltmann, Jürgen. 2004. In the End-the Beginning: The Life of Hope. Trans. Margaret Kohl. Minneapolis, MN: Fortress Press.

Muzzetto, Luigi. 2006. “Time and Meaning in Alfred Schütz.” Time \& Society 15, no. 1: 5-31.

Pedersen, Morten A. 2012. "A Day in the Cadillac: The Work of Hope in Urban Mongolia.” Social Analysis 56, no. 2: 136-151.

Rapport, Nigel. 2003. I Am Dynamite: An Alternative Anthropology of Power. London: Routledge.

Rapport, Nigel. 2010. "Apprehending Anyone: the Non-indexical, Post-cultural, and Cosmopolitan Human Actor." Journal of the Royal Anthropological Institute 16, no. 1: 84-101.

Rosaldo, Renato. 2004. “Grief and a Headhunter's Rage.” 3rd ed. Pp. 579-593 in Anthropological Theory: An Introductory History, ed. R. Jon McGee and Richard L. Warms. New York: McGraw-Hill. 
Steffen, Vibeke, Hanne Jessen, and Richard Jenkins, eds. 2005. Managing Uncertainty: Ethnographic Studies of Illness, Risk and the Struggle for Control. Copenhagen: Museum Tusculanum Press.

Whyte, Susan R. 1997. Questioning Misfortune: The Pragmatics of Uncertainty in Eastern Uganda. Cambridge: Cambridge University Press.

Wilk, Richard. 2009. “The Edge of Agency: Routines, Habits and Volition.” Pp. 143157 in Time, Consumption and Everyday Life: Practice, Materiality and Culture, ed. Elizabeth Shove, Frank Trentmann, and Richard Wilk. Oxford: Berg.

Zigon, Jarrett. 2009. "Hope Dies Last: Two Aspects of Hope in Contemporary Moscow." Anthropological Theory 9, no. 3: 253-271. 